\title{
An institutional review of tumour biology of breast cancer in young Nepalese women
}

\author{
Bikash Nepal', Yogendra Singh ${ }^{1}$, Prakash Sayami ${ }^{1}$, Gita Sayami \\ ${ }^{1}$ Departments of Surgery, Tribhuvan University Teaching Hospital, Kathmandu, Nepal \\ ${ }^{2}$ Departments of Pathology, Tribhuvan University Teaching Hospital, Kathmandu, Nepal
}

Correspondence: Dr Bikash Nepal, Departments of Surgery, Tribhuvan University Teaching Hospital, Kathmandu, Nepal

Email: bikash.nepal3@gmail.com

\begin{abstract}
Introduction: Breast cancers in less than 40 years of age group usually present with aggressive biology and has poor prognosis. The aim of this study was to see clinic-pathological and hormone receptors of breast cancers in young women and compare with less than 40 year age group.

Methods: Prospective analysis of 97 breast cancer in patients less than 40 years out of total 373 patients (26\%) over a period of 8 years (2007 Jan to 2014 Dec) was carried out at the Department of Surgery, Tribhuvan University Teaching Hospital, Kathmandu, Nepal.

Result: Among the young women diagnosed with breast cancer, the mean age was $34.5 \pm 6.2$ years Mean tumour size was larger in younger women $(5 \pm 2.5$ vs $4.5 \pm 2.4 \mathrm{~cm})$. Locally advanced disease was higher in younger patients (55\% vs $47 \%)$. Lymphatic and vascular invasions were higher ( $63 \%$ vs $35 \%$ and $40 \%$ vs $25 \%$ ). Grade II and III tumours was higher ( $56 \%$ vs $25 \%$ ). ER, PR and HER2 positivity was detected in $46.9 \%, 48.9 \%$ and $28.9 \%$ respectively. Significant lower ER or PR expression (34.5\% vs 54\%) was seen in younger women, $\mathrm{p}=.002$. Triple negative tumours (ER -ve, PR -ve and HER2 -ve) was proportionately higher in younger patients $(23 \%$ vs $13.7 \%, \mathrm{p}=.043)$.

Conclusion: Young Nepali women presents one quarter of all female breast cancers, more frequently locally advanced with aggressive tumour biology like ER/PR negative and triple negative breast cancers.
\end{abstract}

Keywords: Breast cancer; ER; HER2 neu; PR.

\section{Introduction}

Breast cancer is the most common cancer in women comprising $23 \%$ of all the cancer in women and is the leading cause of cancer death in women, with an estimated 1.15 million new cases per year ${ }^{1}$. Breast cancer is a heterogeneous group of tumour with variable morphology, behaviour, response to therapy, and molecular profile. Tumour with similar clinic-pathological presentations have different behaviours. Young women develop more aggressive subtypes of breast cancer ${ }^{2}$. Young age remains an independent risk factor for poor survival in breast cancer. Breast cancer incidence rate in young is low compared to elder population but it has unique biological features that are not observed in elder population ${ }^{3}$. Young breast cancer represents $5-7 \%$ of all breast cancer in developed world whereas same incidence rate in developing countries is around $25 \%{ }^{4}$. Young patients tend to have more ERnegative, higher grade, and have increased, Ki-67, and p53 with same HER 2 neu expression ${ }^{5}$. Diagnostic delay often occurs in young patient resulting advanced disease in initial presentation because of younger women themselves unaware of breast cancer and by physicians who are less suspicious of this disease in young patients ${ }^{6}$.

This study has been undertaken to look into incidence and tumour biology of breast cancer represented by the expression of hormone receptor status in young patient age less than 40 years and compare with older population in the same time frame. 


\section{Methods}

This was a prospective study conducted in the Department of Surgery in Tribhuvan University Teaching Hospital, Maharajgunj Kathmandu Nepal from January 2007 to December 2013. Consecutive breast cancer patients who were operated in the institute were included in the study. Early Breast cancer patients were taken for upfront surgery either Modified Radical Mastectomy or Breast Conserving Surgery if qualified. (Figure 1) Locally advanced breast cancer patients were considered for neo-adjuvant chemotherapy and subsequently taken for surgery. Various parameters like demography, clinical history, tumour characteristics, treatment, histopathology and immunohistochemistry for hormone receptor: ER, PR, HER2 neu status were analysed. These parameters were analysed and compared between two age groups age less than 40 years considered as young breast cancer patients and that more than 40 years age group were considered as elder breast cancer patients. Clinic-pathological characteristics and tumour biology as expressed by hormone receptor status were analysed among these two groups.

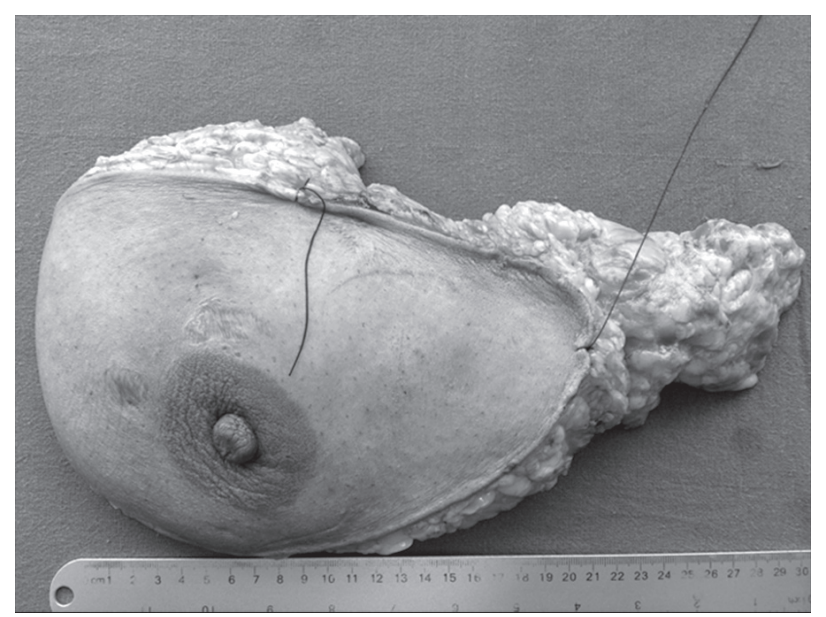

Figure 1: Modified Radical Mastectomy Specimen

The categorical data was analysed using Chi square/ Fisher exact test wherever applicable. The ordinal data like tumour grading was analysed by applying Chi square linear trend test. The student's t test was applied to compare continuous data in two groups. Computer software (SPSS/PC 20 version) was used to analyse the data. All the p-values less than 0.05 was considered as statistically significant.

\section{Results}

Comparative analysis of patient demography, tumour characteristics and tumour biology were done between age less than 40 years and age more than 40 years. Total number breast cancer patients were 373 among them 97 (26\%) were from less than 40 years age whereas 276 (74\%) were from more than 40 years age group. Earliest age presenting with breast cancer is 22 years. Mean age at presentation in less than 40 years age group is $34.5 \pm 6.2$ years and that in more than 40 years age group is $54.1 \pm 9.9$ years. Higher percentage of breast cancer was from age less than 40 years from Tibeto-Burman descent compared to urban residents. (Table 1)

Table.1: Comparison of patient and tumour characteristics

\begin{tabular}{|c|c|c|c|}
\hline Study groups & $\begin{array}{l}<40 \text { years } \\
\text { patients }\end{array}$ & $\begin{array}{l}\geq 40 \text { years } \\
\text { patients }\end{array}$ & p-value \\
\hline Number & $97(26 \%)$ & $276(74 \%)$ & \\
\hline Mean age (years) & $34.5 \pm 6.2$ & $54.1 \pm 9.9$ & \\
\hline Tibeto-Burman & $56(58.2 \%)$ & $135(49.2 \%)$ & 0.045 \\
\hline Urban Residents & $42(56.7 \%)$ & $131(47.4 \%)$ & 0.051 \\
\hline $\begin{array}{l}\text { Mean menarche } \\
\text { age(years) }\end{array}$ & $13.5 \pm 1.5$ & $14.2 \pm 1.5$ & 0.001 \\
\hline $\begin{array}{l}\text { Mean symptom } \\
\text { duration(months) }\end{array}$ & $7.6 \pm 6.5$ & $6.5 \pm 5.7$ & 0.004 \\
\hline $\begin{array}{l}\text { Breast conserving } \\
\text { surgery }\end{array}$ & $27(25.1 \%)$ & $29(8.7 \%)$ & 0.001 \\
\hline $\begin{array}{l}\text { Neoadjuvant } \\
\text { chemotherapy }\end{array}$ & $54(55.1 \%)$ & $126(47.1 \%)$ & 0.001 \\
\hline $\begin{array}{l}\text { Mean tumor } \\
\text { diameter }(\mathrm{cm})\end{array}$ & $5 \pm 2.5$ & $4.5 \pm 2.4$ & 0.005 \\
\hline $\begin{array}{l}\text { Axillary lymph } \\
\text { node positivity }\end{array}$ & $71(73 \%)$ & $163(59 \%)$ & 0.02 \\
\hline $\begin{array}{l}\text { Locally advanced } \\
\text { breast cancer }\end{array}$ & $53(55.1 \%)$ & $130(47.1 \%)$ & 0.049 \\
\hline $\begin{array}{l}\text { Ductal carcinoma } \\
\text { variant }\end{array}$ & $93(93.1 \%)$ & $237(86 \%)$ & 0.4 \\
\hline $\begin{array}{l}\text { Histological grade } \\
\text { II or III }\end{array}$ & $54(55.9 \%)$ & $68(24.5 \%)$ & 0.002 \\
\hline $\begin{array}{l}\text { Lymphatic } \\
\text { invasion }\end{array}$ & $61(63.2 \%)$ & $94(34.3 \%)$ & 0.010 \\
\hline Vascular Invasion & $38(39.8 \%)$ & $70(25.4 \%)$ & 0.020 \\
\hline
\end{tabular}


Mean tumour diameter was statistically significantly higher in age less than 40 years $5 \pm 2.5 \mathrm{~cm}$ compared to $4.5 \pm 2.4$ $\mathrm{cm}$ in age more than 40 years.In age less than 40 years age group $73 \%, 71$ patients out of 97 patients had palpable axillary lymphnodes compared to $59 \%, 163$ out of 276 among age more than 40 years age group. In more than 40 years age group more percentage of patients 55\% (53 out of 97) presented as locally advanced breast cancer compared to $47 \%$ (130 out of 276 ) in more than 40 years age group.

Ninety percentage of breast cancer were of ductal carcinoma variants. Comparing histological grade between two groups Grade II and III tumours were higher in age less than 40 years group presenting as $55.9 \%$ (54 out of 97) compared to $24.5 \%$ (68 out of 276 ) in age more than 40 years age group. Lymphatic invasions were as much as $63.2 \%$ (61 out of 97) in age less than 40 years age group compared to $34.3 \%$ (94 out of 276) in age more than 40 years age group. Vascular invasions were also higher in age less than 40 years $39.8 \%$ (38 out of 97) versus $25.4 \%$ (70 out of 276) in age more than 40 years group.

On Immunohistochemistry analysis overall ER positivity rate $46.9 \%$ (175 out of 373 ), PR positivity rate $48.9 \%$ (182 out of 276) and HER2neu positivity 28.9\% (108 out of 373). We studied hormone receptor status between two groups and compared the tumour biology. ER and/or PR positivity were less among less than 40 years age group $34.5 \%$ (33 out of 97) compared to 54\% (149 out of 276) in age more than 40 years age group. (Table 2) There was not any statistical significant difference in HER 2neu positivity between two groups $26.4 \%$ in age less than 40 years versus $29.8 \%$ in age more than 40 years group. There was statistically significant difference in triple negative breast cancer in age less than 40 years compared to more than 40 years age group. In age less than 40 years age group $23 \%$ (22 out of 97) were triple negative breast cancer compared to $13.7 \%$ (38 out of 276 ) in age more than 40 years age group ( $\mathrm{p}$ value 0.043 ).

Table 2: Comparison of ER PR HER 2 neu expression between two groups

$\begin{array}{llll}\text { Study groups } & \begin{array}{l}<\mathbf{4 0} \text { years } \\ \text { patients }\end{array} & \begin{array}{l}\mathbf{2 0} \text { years } \\ \text { patients }\end{array} & \begin{array}{l}\text { p- } \\ \text { value }\end{array} \\ \begin{array}{l}\text { ER \&/or PR } \\ \text { positivity }\end{array} & 33 / 97 & 149 / 276 & 0.002 \\ \text { HER2 positivity } & 26 / 97 & 82 / 276 & 0.595 \\ & (26.5 \%) & (54 \%) & \\ \text { Triple negative } & 27 / 97 & 38 / 276 & 0.043 \\ \text { tumors } & (23 \%) & (13.7 \%) & \end{array}$

\section{Discussion}

Young breast cancer presents with different tumour morphology and tumour biology compared to older patients. Young breast cancer patients usually present late and present with aggressive cancer and with adverse tumour biology compared to older breast cancer ${ }^{7}$. Incidence of young breast cancer is low in developed country corresponding to around $5-7 \%$ whereas incidence in Asian countries is high $25 \%$ being diagnosed at less than 40 years $^{8}$. Young breast cancer comprises of $26 \%$ of total breast cancer patients in our study. Younger patients presented late mean duration of symptoms 7.6 \pm 6.5 months versus $6.5 \pm 5.7$ in more than 40 years age group which was significant statistically.The diagnostic delay in young patients is usually due to patients themselves, as they are often less concerned about and aware of breast cancer, and by physicians, who have less suspicion of this disease in younger women ${ }^{9}$. Palpable lymph nodes present in axillae breast cancer represent aggressive and likely to have systemic disease compared to non-palpable axillary lymph nodes ${ }^{10}$.Young breast cancer patients had axillary lymph nodes palpable in $73 \%$ of the patients compared to $59 \%$ in breast cancer patients in age more than 40 years age group. Young breast cancer patients were more of locally advanced breast cancer $55 \%$ compared to $47.1 \%$ in age more than 40 years patient. Tumour size and lympangioinvasion is independent indicator of node negative breast cancer. Lymphangio-invasion is a measure of metastatic potential that becomes severe when the tumour size is large ${ }^{11}$. Ductal carcinoma of breast was major variant of breast cancer in this study accounting for $93.1 \%$. Higher pathological grade of tumour, grade II and III was present in young breast cancer patients. Young breast cancer patients present with significant high percentage of lymphatic and vascular emboli in their pathological specimen compared to old breast cancer patients. Young breast cancer patients presents with aggressive histopathology indicator.

ER receptor pathway plays a critical role in the pathophysiology of human breast cancer. ER receptor is a well-established predictive and prognostic factor in breast cancer patients ${ }^{12}$. PR is surrogate marker for ER. Overexpression of PR indicates that ER receptor pathway is intact even if ER is reported as negative. ER positive patients usually benefit from targeted hormonal therapy in adjuvant or palliative setting. ER positive tumours have usual association with older age, favourable nuclear histology and low proliferative index ${ }^{13}$. Lack of ER receptor has been consistently associated with poorer prognosis ${ }^{14}$. In this study, ER positivity is less in age less than 40 years age group $34.5 \%$ compared to $54 \%$ ER positivity in older age 
group patients which had significant $p$ value. HER2 neu another proliferative marker in breast cancer is associated with poor disease free survival rate in lymph node positive cancer patients ${ }^{15}$. However, this study showed no difference in expression of HER2neu receptor between young breast cancer patients and old breast cancer patients.

Triple negative breast cancer (TNBC) associated with distinct clinical and pathologic characteristics such as diagnosis at younger age and with higher grade ${ }^{16}$. Lack of established receptors reduces the therapeutic options and remains a challenge to treat by targeted therapy ${ }^{17}$. Patients with BRCA1 mutation tend to have ER, PR and HER 2 neu receptors negative and presents with higher grade ${ }^{18}$. In this study, there is statistically significant high percentage of triple negative breast cancer in less than 40 years age group compared to more than 40 years age group patients. Breast tumour biology is more aggressive and is associated with an unfavourable prognosis in younger women ${ }^{19}$. In this study, young breast cancer patients was found to have adverse tumour biology with more patients with TNBC, more patients with ER negative tumour,more of lymph node positivity and with higher grade compared to old breast cancer patients.

\section{Conclusion}

Young Nepalese women present one quarter of all female breast cancers, more frequently locally advanced with aggressive tumour biology like ER/PR negative and triple negative breast cancers.

\section{References}

1. Parkin DM, Bray F, Ferlay J, Pisani P. Global cancer statistics, 2002. CA Cancer J Clin 2005; 55: 74-108

2. Freedman RA, Partridge AH. Management of breast cancer in very young women. Breast,2013;2:176-9

3. Stewart BW, Wild C; International Agency for Research on Cancer; World Health Organization. World Cancer Report 2014. Geneva: World Health Organization; 2014

4. Brinton LA, Sherman ME, Carreon JD, Anderson WF. Recent Trends in Breast Cancer Among Younger Women in the United States. JNCI Journal of the National Cancer Institute. 2008;100:1643-1648.

5. Figueroa JD, Brinton LA. Unraveling Genes, Hormones, and Breast Cancer.JNCI Journal of the National Cancer Institute. 2012;104:641-642.

6. Barber MD, Jack W, Dixon JM. Diagnostic delay in breast cancer. Br J Surg 2004;91:49-53

7. Sidoni A, Cavaliere A, Bellezza G, Scheibel M, Bucciarelli E. Breast cancer in young women: Clinicopathological features and biological specificity. Breast 2003;12:247-50

8. Barber MD, Jack W, Dixon JM. Diagnostic delay in breast cancer. Br J Surg 2004;91:49-53.

9. Friedman LC, Kalidas M, Elledge R, Dulay MF, Romero C, Chang J, et al. Medical and psychosocial predictors of delay in seeking medical consultation for breast symptoms in women in a public sector setting. $\mathrm{J}$ Behav Med 2006;29:327-34

10. Gurleyik G, Gurleyik E, Aktekin A, Aker F. Preoperative Assessment of the Axilla by Surgeon Performed Ultrasound and Cytology in Patients With Breast Cancer. Journal of Clinical Medicine Research. 2015;7:440-445.

11. John S Meyer, Consuelo Alvarez, Clara Milikowski, Neal Olson, Irma Russo,Jose Russo, Andrew Glass, Barbara A Zehnbauer:Breast carcinoma malignancy grading by Bloom-Richardson system vs proliferation index: reproducibility of grade and advantages of proliferation index. Modern Pathology 2005,18:1067-1078

12. Speirs V, Kerin MJ: Prognostic significance of oestrogen receptor beta in breast cancer. Br J Surg 2000, 87:405-409.

13. Donegan WL: Tumor-related prognostic factors for breast cancer. CA Cancer J Clin 1997, 47:28-51

14. Skoog L, Humla S, Axelsson M, Frost M, Norman A, Nordenskjold B, Wallgren A: Estrogen receptor levels and survival of breast cancer patients. A study on patients participating in randomized trials of adjuvant therapy. ActaOncol 1987, 26:95-100

15. Slamon DJ, Clark GM, Wong SG, Levin WJ, Ullrich A, McGuire WL: Human breast cancer: correlation of relapse and survival with amplification of the HER-2/ neu oncogene. Science 1987, 235:177-182

16. Anders C, Carey LA: Understanding and treating triplenegative breast cancer. Oncology.2008, 22:1233-1239.

17. Irvin WJ Jr, Carey LA: What is triple-negative breast cancer? Eur J Cancer.2008 44:2799-2805

18. Rakha EA, Reis-Filho JS, Ellis IO: Basal-like breast cancer: A critical review. J Clin Oncol.2008, 26: 25682581.

19. Han-Byoel Lee1, Wonshik Han. Unique Features of Young Age Breast Cancer and Its Management. J Breast Cancer 2014; 17: 301-307 